\title{
Regulation of peripheral vascular tone in patients with heart failure: contribution of angiotensin II
}

\author{
D E Newby, N E R Goodfield, A D Flapan, N A Boon, K A A Fox, D J Webb
}

Clinical Pharmacology Unit and Research Centre, University of Edinburgh, Western General Hospital, Crewe Road, Edinburgh, UK D E Newby D J Webb

Cardiovascular Research Unit, University of Edinburgh, Royal Infirmary, Lauriston Place, Edinburgh, UK A D Flapan

N A Boon

K A A Fox

Department of Cardiology, Stobhill Hospital, Balornock Road, Glasgow, UK N E R Goodfield

Correspondence to: Dr D E Newby, Clinical Pharmacology Unit and Research Centre, University of Edinburgh, Western General Hospital, Crewe Road, Edinburgh EH4 2XU, UK.

email: D.E.Newby@ed.ac.uk

Accepted for publication 17 March 1998

\begin{abstract}
Objective-To determine directly the contribution of angiotensin II to basal and sympathetically stimulated peripheral arteriolar tone in patients with heart failure. Design-Parallel group comparison. Subjects-Nine patients with New York Heart Association grade II-IV chronic heart failure, and age and sex matched controls.
\end{abstract}

Interventions-Forearm plethysmography, lower body negative pressure, local intra-arterial administration of losartan, angiotensin II, and noradrenaline, and estimation of plasma hormone concentrations.

Main outcome measures-Forearm blood flow responses, plasma hormone concentrations.

Results-Baseline blood pressure, heart rate, and forearm blood flow did not differ between patients and controls. In comparison with the non-infused forearm, losartan did not affect basal forearm blood flow $(95 \%$ confidence interval $-5.5 \%$ to $\mathbf{+ 7 . 3 \%}$ ) or sympathetically stimulated vasoconstriction in controls. However, the mean (SEM) blood flow in patients increased by $13(5) \%$ and $26(7) \%$ in response to 30 and $90 \mu \mathrm{g} / \mathrm{min}$ of losartan respectively $(p<0.001)$. Lower body negative pressure caused a reduction in forearm blood flow of $20(5) \%$ in controls $(p=0.008)$ and $13(5) \%(p=0.08)$ in patients $(p=0.007$, controls $v$ patients $)$. Blood flow at $90 \mu \mathrm{g} / \mathrm{min}$ of losartan correlated with plasma angiotensin II concentration $(r=0.77 ; p=0.03)$. Responses to angiotensin II and noradrenaline did not differ between patients and controls.

Conclusions-Losartan causes acute local peripheral arteriolar vasodilatation in patients with heart failure but not in healthy control subjects. Endogenous angiotensin II directly contributes to basal peripheral arteriolar tone in patients with heart failure but does not augment sympathetically stimulated peripheral vascular tone.

(Heart 1998;80:134-141)

Keywords: angiotensin II; heart failure; peripheral vascular tone; sympathetic nervous system

Angiotensin II is a potent vasoconstrictor and pressor peptide, playing a fundamental role in the regulation of blood pressure and body sodium and water under circumstances of sodium and volume depletion. ${ }^{1}$ All the major effects of angiotensin II are mediated through the angiotensin II type 1 ( $\left.\mathrm{AT}_{1}\right)$ receptor, and include arteriolar vasoconstriction, renal sodium reabsorption, and stimulation of adrenal aldosterone production. ${ }^{1}$ Within minutes of acute hypovolaemia, renin secretion causes rapid generation of angiotensin II, leading to compensatory vasoconstriction and fluid retention that serves to sustain blood pressure and prevent circulatory collapse. ${ }^{2}$ Even at doses insufficient to cause vasoconstriction directly, angiotensin II augments sympathetically mediated vasoconstriction ${ }^{3}$ through a prejunctional adrenoreceptor mediated mechanism. ${ }^{4}$ Thus angiotensin II has the potential to be a major contributor to the physiological regulation of vascular tone and blood pressure in man.

The renin-angiotensin system also plays a central role in the pathophysiology of heart failure. Decreased renal perfusion secondary to low cardiac output increases renin production, which in turn leads to increased generation of angiotensin II. The vasoconstrictor and salt and water retaining properties of angiotensin II increase cardiac work, leading to a vicious circle of worsening heart failure-hence the rationale for using ACE inhibitor treatment in patients with heart failure to interrupt this damaging maladaptive response. This paradigm has been confirmed in many clinical heart failure studies in terms of clinical status and exercise time, ${ }^{67}$ and long term effects on morbidity and mortality. ${ }^{8-11}$ However, ACE inhibitors not only block the generation of angiotensin II from angiotensin I, but also inhibit the degradation of other peptides such as bradykinin and substance P. Thus the mechanisms whereby ACE inhibition achieves these beneficial effects in heart failure are unclear and may not be directly attributable to a reduction in plasma angiotensin II concentrations. ${ }^{12}$

Systemic $\mathrm{AT}_{1}$ antagonism in patients with heart failure causes a reduction in blood pressure and systemic vascular resistance. ${ }^{13}{ }^{14}$ However, when examining in vivo vascular responses in man, systemic drug administration causes concomitant effects on organs such as the brain, kidney, and heart, and influences neurohumoral reflexes through changes in systemic haemodynamics. Because of these confounding influences, vascular responses cannot be wholly attributed to a direct effect of the drug in blood vessels. ${ }^{15}{ }^{16}$ In contrast, the use of bilateral forearm blood flow measurementswith unilateral brachial artery infusion of vasoactive drugs at subsystemic, locally active doses-provides a powerful and reproducible method of directly assessing vascular responses in vivo. ${ }^{1516}$ This technique has been used very 
successfully to demonstrate the major contribution of nitric oxide and endothelin-1 to the maintenance of basal peripheral vascular tone in healthy people. ${ }^{17} 18$

Previous local forearm studies assessing the role of the renin-angiotensin system in the maintenance of basal peripheral vascular resistance ${ }^{1920}$ have been confounded by the use of antagonists, such as saralasin, with partial agonist activity. However, losartan, a selective $\mathrm{AT}_{1}$ receptor antagonist devoid of agonist activity, has recently become available for clinical use. The aims of our study were thus to investigate patients with heart failure and matched healthy controls as follows: first, to establish the role of endogenous angiotensin II in the maintenance of peripheral vascular tone; second, to determine the effect of sympathetically stimulated vasoconstriction in the presence and absence of angiotensin II antagonism; and third, to document the peripheral vascular responses to noradrenaline and angiotensin II.

\section{Methods}

SUBJECTS

We recruited nine patients with established chronic heart failure of New York Heart Association (NYHA) grade II-IV who were taking maintenance ACE inhibitor treatment. They had a left ventricular ejection fraction of $<35 \%$ or echocardiographic evidence of left ventricular impairment (shortening fraction of $<20 \%$ or left ventricular end diastolic diameter of $>5.6 \mathrm{~cm}$ ), or both. Age and sex matched controls were also recruited. All studies were undertaken with the approval of the local research ethics committee and the written informed consent of each subject.

None of the control subjects received vasoactive or non-steroidal anti-inflammatory drugs in the week before each phase of the study, and all abstained from alcohol for 24 hours and from food and caffeine containing drinks for at least nine hours before each study. Patients were withdrawn from ACE inhibitor treatment for five drug half lives before each of the study days. All other concomitant drugs were omitted on the study day. All studies were performed in a quiet, temperature controlled room maintained at $23.5-24.5^{\circ} \mathrm{C}$.

DRUGS

Losartan (Dupont-Merck, Wilmington, USA), noradrenaline (Levophed; Sanofi Winthrop, Guildford, UK), and angiotensin II (Clinalfa AG, Läufelfingen, Switzerland) were dissolved in physiological saline and given intraarterially. To prevent its oxidation, noradrenaline was dissolved in saline containing $0.1 \%$ ascorbic acid (Evans Medical, Langhurst, UK). Doses of losartan (30-90 $\mu \mathrm{g} / \mathrm{min})$ were chosen to achieve an effective subsystemic and locally active concentration. ${ }^{2122}$

INTRA-ARTERIAL ADMINISTRATION

The brachial artery of the non-dominant arm was cannulated with a 27 gauge steel needle (Cooper's Needle Works, Birmingham, UK) under 1\% lignocaine (Xylocaine; Astra Pharmaceuticals, Kings Langley, UK) local anaes- thesia. The cannula was attached to a 16 gauge epidural catheter (Portex, Hythe, UK) and patency maintained by infusion of physiological saline through a syringe pump. The total rate of intra-arterial infusions was maintained constant throughout all studies at $1 \mathrm{ml} / \mathrm{min}$.

FOREARM BLOOD FLOW AND BLOOD PRESSURE Blood flow was measured in both the infused and non-infused forearms by venous occlusion plethysmography using mercury-in-Silastic strain gauges applied to the widest part of the forearm. ${ }^{15}$ During measurement periods the hands were excluded from the circulation by rapid inflation of the wrist cuffs to a pressure of $220 \mathrm{~mm} \mathrm{Hg}$ using E20 Rapid Cuff Inflators (D E Hokanson, Washington DC, USA). Upper arm cuffs were inflated intermittently to 40 $\mathrm{mm} \mathrm{Hg}$ for 10 seconds in every 15 seconds to achieve venous occlusion and obtain plethysmographic recordings. Analogue voltage output from an EC-4 strain gauge plethysmograph (D E Hokanson) was processed by a MacLab analogue to digital converter and Chart v3.3.8 software (AD Instruments, Castle Hill, Australia) and recorded onto a MacIntosh Classic II computer (Apple Computers, Cupertino, USA). Calibration was achieved using the internal standard of the plethysmograph.

Blood pressure was monitored in the noninfused arm at intervals throughout each study, using a semi-automated non-invasive oscillometric sphygmomanometer ${ }^{23}$ (Takeda UA 751, Takeda Medical, Tokyo, Japan).

\section{LOWER BODY NEGATIVE PRESSURE}

Subjects were rested supine in a plastic covered steel cage enclosing the lower body from the waist, as described previously. ${ }^{3}$ Suction was applied using an industrial strength vacuum cleaner regulated by a servo control unit (Medical Physics Department, Edinburgh, UK) to produce a constant negative pressure of $15 \mathrm{~mm} \mathrm{Hg}$. Alteration to and from atmospheric pressure was attained within one to two seconds.

\section{VENOUS SAMPLING AND ASSAYS}

Ten minutes before giving losartan by infusion and 10 minutes after its completion, $30 \mathrm{ml}$ of blood was withdrawn from the non-infused arm and $10 \mathrm{ml}$ admixed with each of $1 \mathrm{ml}$ of $1 \%$ disodium EDTA, $0.5 \mathrm{ml}$ of $0.45 \%$ $O$-phenanthroline $/ 4.65 \%$ disodium EDTA, and $1 \mathrm{ml}$ of $1 \%$ disodium EDTA $/ 2 \%$ sodium metabisulphite. The samples were placed on ice and immediately centrifuged at $2000 \times g$ for 15 minutes. Plasma was frozen and stored at $-80^{\circ} \mathrm{C}$ before assay for plasma angiotensin II, endothelin-1, big endothelin-1, adrenaline, and noradrenaline concentrations. Following extraction using Bond Elut columns (Varian, Harbor City, California, USA), ${ }^{24}$ concentration of plasma angiotensin II (Peninsula Laboratories Europe, St Helens, UK), endothelin-1 (Peninsula Laboratories Europe), and big endothelin-1 (Peninsula Laboratories Europe) were determined by radioimmunoassay as previously described. ${ }^{25}{ }^{26}$ The intra-assay coefficients of variability were 
$5.2 \%, 7.0 \%$, and $7.2 \%$, respectively, and the interassay coefficients of variability were $8.6 \%$, $9.0 \%$, and $9.3 \%$, respectively. The cross reactivities of the endothelin-1 assay were as follows: endothelin-1 (100\%), endothelin-2 (7\%), endothelin-3 (7\%), big endothelin-1 $(10.3 \%)$, C-terminal fragment $(0 \%)$, angiotensin I $(0 \%)$, and angiotensin II $(0 \%)$. The cross reactivities of the big endothelin-1 assay were as follows: endothelin-1 (0\%), endothelin-2 $(0 \%)$, endothelin-3 $(0 \%)$, big endothelin-1 $(100 \%)$, C-terminal fragment $(100 \%)$, and brain natriuretic peptide-32 $(0 \%)$. Adrenaline and noradrenaline concentrations were determined by an electrochemical method after separation by reverse phase high performance liquid chromatography. ${ }^{27}$

\section{STUDY DESIGN}

Subjects attended at 09:00 and rested recumbent throughout each study. Strain gauges and cuffs were applied and the brachial artery of the non-dominant arm cannulated. Measurements of forearm blood flow were made for the last three minutes of each infusion period unless otherwise stated. Before participating in one of the following protocols, saline was infused for the first 30 minutes to allow time for equilibration, with forearm blood flow measurements being made every 10 minutes and basal blood flow being taken as the last of these measurements.

Eight patients with heart failure and eight matched healthy controls received saline, losar$\tan 30 \mu \mathrm{g} / \mathrm{min}$, losartan $90 \mu \mathrm{g} / \mathrm{min}^{21}{ }^{22}$ and saline, each for 13 minutes and in that order. Forearm blood flow was measured continuously for the last six minutes of each infusion,

Table 1 Subject characteristics

\begin{tabular}{|c|c|c|}
\hline & $\begin{array}{l}\text { Control } \\
\text { subjects }\end{array}$ & $\begin{array}{l}\text { Patients with } \\
\text { heart failure }\end{array}$ \\
\hline Mean (SD) age (years) & $61(4)$ & $64(2)$ \\
\hline $\operatorname{Sex}(M / F)$ & $6 / 3$ & $6 / 3$ \\
\hline Aetiology ischaemic heart disease & - & 9 \\
\hline NYHA grade II/III/IV & - & $5 / 3 / 1$ \\
\hline Left ventricular ejection fraction (\%) & - & $30(2)$ \\
\hline \multicolumn{3}{|l|}{ Echocardiography } \\
\hline $\operatorname{LVEDD}(\mathrm{cm})$ & - & $7.2(0.5)$ \\
\hline $\mathrm{SF}(\%)$ & - & $16(2)$ \\
\hline \multicolumn{3}{|l|}{ Concomitant treatment } \\
\hline ACE inhibitor & - & 9 \\
\hline Diuretic & - & 9 \\
\hline Aspirin & - & 9 \\
\hline Nitrates & - & 5 \\
\hline$\beta$ Blocker & - & 3 \\
\hline Calcium antagonist & - & 3 \\
\hline Digoxin & - & 2 \\
\hline Amiodarone & - & 1 \\
\hline \multicolumn{3}{|l|}{ Blood pressure $(\mathrm{mm} \mathrm{Hg})$} \\
\hline Systolic & $132(5)$ & $132(9)$ \\
\hline Diastolic & $82(5)$ & $81(6)$ \\
\hline Heart rate (beats/min) & $66(3)$ & $64(2)$ \\
\hline \multicolumn{3}{|l|}{ Baseline blood flow $(\mathrm{ml} / 100 \mathrm{ml} / \mathrm{min})$} \\
\hline Infused & $4.2(0.7)$ & $2.8(0.3)^{\star}$ \\
\hline Non-infused & $3.7(0.6)$ & $2.6(0.2)^{\star}$ \\
\hline Plasma endothelin-1 (fmol/ml) & $1.9(0.3)$ & $3.0(0.1) \dagger$ \\
\hline Plasma big endothelin-1 (fmol/ml) & $7.9(2.0)$ & $19.6(3.5) \ddagger$ \\
\hline \multicolumn{3}{|l|}{ Plasma angiotensin II (fmol/ml) } \\
\hline Basal & $3.3(0.3)$ & $13.3(9.6) \S$ \\
\hline After losartan & $3.3(0.4)$ & $9.1(3.9) \S$ \\
\hline Plasma noradrenaline ( $\mathrm{pmol} / \mathrm{ml})$ & $1.6(0.5)$ & $1.3(0.1)$ \\
\hline Plasma adrenaline $(\mathrm{pmol} / \mathrm{ml})$ & $0.3(0.1)$ & $1.3(0.6)$ \\
\hline
\end{tabular}

${ }^{\star} \mathrm{p}=0.11 ; \mathrm{tp}=0.005 ; \neq \mathrm{p}=0.01 ; \mathrm{p}=0.08 ; \uparrow \mathrm{p}=0.16$.

$\mathrm{ACE}$, angiotensin converting enzyme; LVEDD, left ventricular end diastolic dimension; NYHA, New York Heart Association; $\mathrm{SF}$, shortening fraction. with lower body negative pressure being applied for the last three minutes. Following 15 minutes of further saline infusion, noradrenaline was infused intra-arterially at doses of 20 , 60,180 , and $540 \mathrm{pmol} / \mathrm{min},{ }^{22}$ each for six minutes. At least one week later, subjects reattended and received incremental doses of angiotensin II $(0.1,1,10$, and $100 \mathrm{pmol} / \mathrm{min}),{ }^{22}$ each dose given into the brachial artery for six minutes. One patient withdrew after the first visit and was replaced.

DATA ANALYSIS AND STATISTICS

Plethysmographic data were extracted from the chart data files and forearm blood flows were calculated for individual venous occlusion cuff inflations by use of a template spreadsheet (Excel v5.0; Microsoft). Recordings from the first 60 seconds after wrist cuff inflation were not used because this causes reflex vasoconstriction. ${ }^{15}{ }^{16}$ Usually, the last five flow recordings in each three minute measurement period were calculated and averaged for each arm. To reduce the variability of blood flow data, the ratio of flows in the two arms was calculated for each time point, in effect using the non-infused arm as a contemporaneous control for the infused arm. ${ }^{15}{ }^{16}$ Percentage changes in the infused forearm blood flow were calculated $^{15}{ }^{16}$ as follows:

$$
\begin{gathered}
\% \text { Change in blood flow }= \\
100 \times\left\{\mathrm{I}_{\mathrm{t}} / \mathrm{NI}_{\mathrm{t}}-\mathrm{I}_{\mathrm{b}} / \mathrm{NI}_{\mathrm{b}}\right\} / \mathrm{I}_{\mathrm{b}} / \mathrm{NI}_{\mathrm{b}}
\end{gathered}
$$

where $I_{b}$ and $\mathrm{NI}_{b}$ are the infused and noninfused forearm blood flows at baseline (time 0 ), respectively, and $\mathrm{I}_{t}$ and $\mathrm{NI}_{\mathrm{t}}$ are the infused and non-infused forearm blood flows at a given time point.

Data were examined by analysis of variance (ANOvA) with repeated measures, two tailed paired Student's $t$ test, and regression analysis using Excel v5.0. All results are expressed as mean (SEM). Significance was taken at the 5\% level.

\section{Results}

Patients had significantly higher plasma endothelin-1 and big endothelin-1 concentrations than controls (table 1), with a trend for higher plasma angiotensin II and adrenaline concentrations.

There were no significant differences in blood pressure, heart rate, or baseline forearm blood flows in the infused and non-infused arms between protocols, or between patient and control subjects. Throughout all studies there were no significant changes in heart rate or arterial pressure (table 2; data on file). Except during the application of lower body negative pressure, there were no significant changes in blood flow in the non-infused arm. Plasma angiotensin II concentrations did not change significantly during the study (table 1).

In the healthy control subjects, there were no significant changes in blood flow of the infused forearm during infusions of saline or losartan (fig 1). Student's $t$ distribution gives $95 \%$ confidence intervals of $-5.5 \%$ to $+7.3 \%$ and $-9.7 \%$ to $+6.9 \%$ for percentage changes in forearm blood flow with $30 \mu \mathrm{g} / \mathrm{min}$ and 90 
Table 2 Systemic haemodynamics, forearm blood flow, and lower body negative pressure (LBNP) responses during saline and losartan infusions

\begin{tabular}{|c|c|c|c|c|c|c|c|c|}
\hline & \multicolumn{4}{|c|}{ Control subjects $(n=8)$} & \multicolumn{4}{|c|}{ Patients with heart failure $(n=8)$} \\
\hline & Saline & $\begin{array}{l}\text { Losartan } \\
30 \mu \mathrm{g} / \mathrm{min}\end{array}$ & $\begin{array}{l}\text { Losartan } \\
90 \mu \mathrm{g} / \mathrm{min}\end{array}$ & Saline & Saline & $\begin{array}{l}\text { Losartan } \\
30 \mu \mathrm{g} / \mathrm{min}\end{array}$ & $\begin{array}{l}\text { Losartan } \\
90 \mu \mathrm{g} / \mathrm{min}\end{array}$ & Saline \\
\hline \multicolumn{9}{|l|}{ Blood pressure $(\mathrm{mm} \mathrm{Hg})$} \\
\hline Systolic & $129(4)$ & $132(4)$ & $128(5)$ & $133(4)$ & $134(9)$ & $134(9)$ & $139(9)$ & $133(9)$ \\
\hline Diastolic & $86(4)$ & $86(6)$ & $85(3)$ & $83(3)$ & $83(6)$ & $85(7)$ & $85(6)$ & $81(6)$ \\
\hline Heart rate (beats/min) & $74(3)$ & $68(3)$ & $65(4)$ & $63(3)$ & $64(2)$ & $63(2)$ & $62(2)$ & $63(2)$ \\
\hline \multicolumn{9}{|c|}{ Absolute forearm blood flow $(\mathrm{ml} / 100 \mathrm{ml} / \mathrm{min})$} \\
\hline Non-infused arm & $3.8(0.7)$ & $4.1(1.0)$ & $4.2(1.0)$ & $4.8(1.2)$ & $2.9(0.5)$ & $2.7(0.3)$ & $2.7(0.2)$ & $2.6(0.2)$ \\
\hline Infused arm & $4.3(0.8)$ & $4.7(1.2)$ & $4.7(1.2)$ & $4.8(1.1)$ & $3.1(0.5)$ & $3.4(0.5)$ & $3.6(0.4)$ & $3.2(0.5)^{\star}$ \\
\hline \multicolumn{9}{|l|}{ Percentage change in } \\
\hline forearm blood flow & $1(2)$ & $1(3)$ & $-1(4)$ & $-5(5)$ & $0(2)$ & $13(5)$ & $26(7)$ & $12(5) \dagger$ \\
\hline \multicolumn{9}{|c|}{ Absolute forearm blood flow with $\mathrm{LBNP}(\mathrm{ml} / 100 \mathrm{ml} / \mathrm{min})$} \\
\hline Non-infused arm & $3.1(0.6)$ & $3.3(0.8)$ & $3.3(0.8)$ & $3.5(0.9)$ & $2.4(0.3)$ & $2.4(0.3)$ & $2.3(0.2)$ & $2.3(0.2)$ \\
\hline Infused arm & $3.4(0.7)$ & $3.5(0.9)$ & $3.7(1.0)$ & $4.0(1.2)$ & $2.5(0.3)$ & $2.8(0.4)$ & $3.0(0.2)$ & $2.7(0.3)$ \\
\hline \multicolumn{9}{|c|}{ Percentage vasoconstriction with LBNP } \\
\hline Non-infused arm & $19(4)$ & $20(4)$ & $21(2)$ & $20(5) \ddagger$ & $13(5)$ & $11(4)$ & $12(5)$ & $13(3)$ \\
\hline Infused arm & $20(5)$ & $24(3)$ & $24(4)$ & $18(4) \ddagger$ & $14(6)$ & $15(4)$ & $15(5)$ & $14(5)$ \\
\hline
\end{tabular}

${ }^{\star} \mathrm{p}<0.001$ (two way ANOva: infused $v$ non-infused); $\nmid \mathrm{p}<0.001$ (two way ANOva: patients $v$ controls); $\neq \mathrm{p}=0.008$ (two way ANOva: basal $v$ LBNP).

$\mu \mathrm{g} / \mathrm{min}$ of intra-arterial losartan, respectively. During saline infusion, lower body negative pressure caused a $20(5) \%$ and a $19(4) \%$ reduction in the infused and non-infused forearm blood flow, respectively (table 2; $\mathrm{p}=0.008)$. There were no significant differences between the vasoconstriction induced by the application of lower body negative pressure in the infused and non-infused arms across the saline and losartan infusion periods (fig 1 and table 2).

In patients with heart failure, blood flow increased by $13.3 \%$ (95\% confidence interval +2.3 to $+24.4 \%)$ and $25.6 \%$ (+9.1 to $+42.2 \%)$ in the infused forearm with $30 \mu \mathrm{g} / \mathrm{min}$ and 90 $\mu \mathrm{g} / \mathrm{min}$ of intra-arterial losartan, respectively $(\mathrm{p}<0.001$; fig 1$)$. The increase in blood flow at $90 \mu \mathrm{g} / \mathrm{min}$ of losartan correlated with the baseline plasma angiotensin II concentration $(r=0.77 ; \mathrm{p}=0.03)$. Lower body negative pressure did not significantly reduce the blood

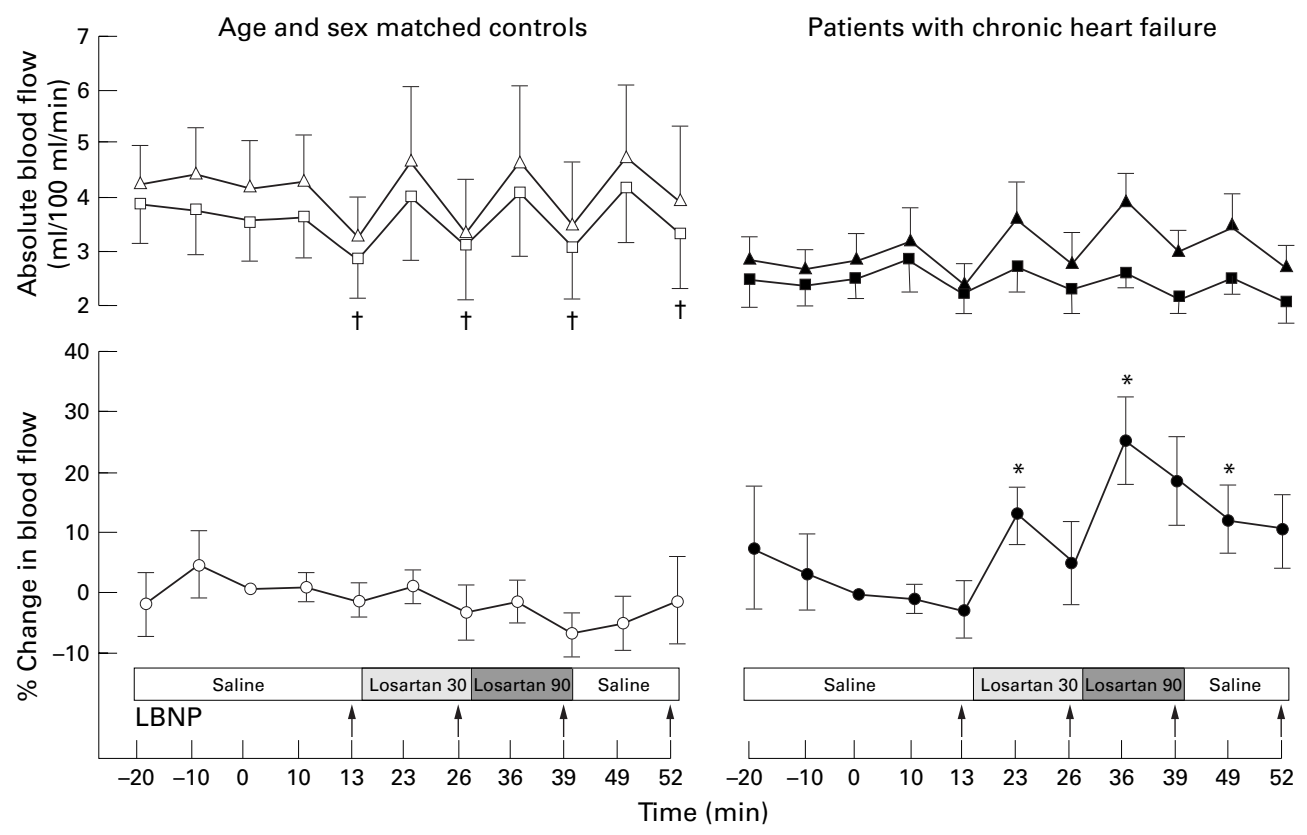

flow in either arm $(p=0.08)$ and was unaffected by losartan in the infused forearm (fig 1 and table 2). The lower body negative pressure response was significantly less than that achieved in the control subjects ( $p=0.007$; fig 1 and table 2).

Angiotensin II and noradrenaline caused dose dependent vasoconstriction in both patients and controls ( $p<0.001$ for all; fig 2). There was no significant difference in the magnitude of the vasoconstriction response to noradrenaline or angiotensin II between patients and controls.

\section{Discussion}

We have previously shown in healthy volunteers ${ }^{22}$ that intra-arterial losartan infusion, at doses of $30-300 \mu \mathrm{g} / \mathrm{min}$, is locally active only and is able to reverse the vasoconstriction caused by angiotensin II infusion at $1 \mathrm{pmol} / \mathrm{min}$ within six minutes. This dose of angiotensin II is

Figure 1 Absolute (non-infused arm, squares; infused arm, triangles) and percentage change in forearm blood flow responses (circles), with intermittent application (arrows) of lower body negative pressure (LBNP), to saline and losartan (30 and $90 \mu \mathrm{g} / \mathrm{min}$ ) infusion in healthy control subjects (empty symbols) and patients with heart failure (filled symbols). ${ }^{*} p<0.001$ (one way ANOVA, $v$ baseline saline infusion) $; \nmid p=0.008$ (two way ANOVA, basal $v$ LBNP). 


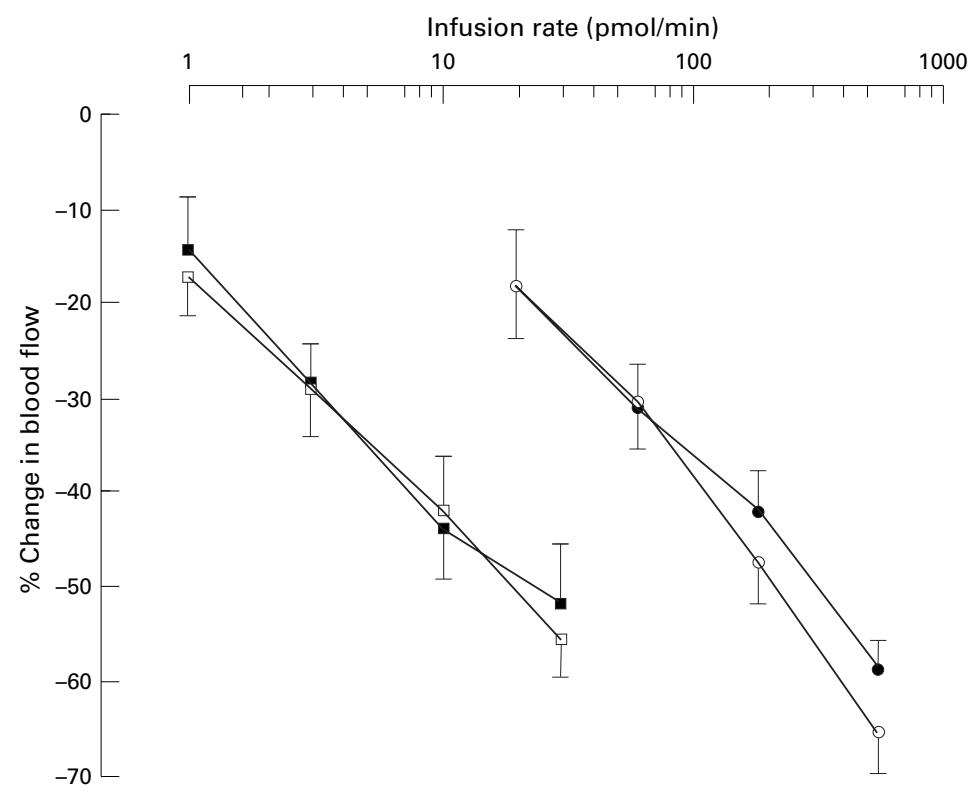

Figure 2 Forearm blood flow responses to infusion of angiotensin II (squares) and noradrenaline (circles) in healthy control subjects (empty symbols) and patients with heart failure (filled symbols); $p<0.001$ (one way ANOVA for each response).

sufficient to cause a comparable increase in plasma angiotensin II to that seen in patients with heart failure and causes a reduction in blood flow of about $20 \%$. In the present study, we have shown for the first time that brachial artery infusion of losartan causes an acute local increase in forearm blood flow by $\sim 25 \%$ in patients with heart failure. This cannot be explained by an increased sensitivity to angiotensin II in these patients, given the normal dose-response relations to angiotensin II infusion. Moreover, the mean plasma angiotensin II concentrations tended to be higher in patients with heart failure and the maximum increase in blood flow in the infused arm significantly correlated with plasma angiotensin II concentrations. These findings suggest that in patients with heart failure, endogenous angiotensin II contributes to the maintenance of basal peripheral vascular tone. The observed reductions in systemic vascular resistance with oral losartan ${ }^{13} 1428$ would therefore appear to be related to the direct vasodilator action of $\mathrm{AT}_{1}$ antagonism on peripheral resistance vessels.

One of the first vasodilator treatment trials in heart failure (V-HeFT I) ${ }^{29}$ showed significant benefit for left ventricular function and mortality using the combination of isosorbide dinitrate and hydralazine, but not prazosin. It would appear, therefore, that all vasodilators are not equal and the precise mechanisms by which some agents, but not others, produce benefit remain unclear. In patients with heart failure, acute systemic $\mathrm{AT}_{1}$ antagonism and ACE inhibition reduce systemic vascular resistance and blood pressure to a similar extent. ${ }^{131428}$ However, ACE inhibition also has the potential to cause the accumulation of endogenous vasodilating peptides such as bradykinin and substance $P$, which raises the possibility that the resultant vasodilatation may not be solely attributable to a reduction in angiotensin II generation. Indeed, there is evi- dence that endogenous bradykinin may regulate arteriolar tone in some vascular beds ${ }^{30}$ and that some of the beneficial effects of ACE inhibition in heart failure may be mediated through bradykinin. ${ }^{12}$ However, our findings of a direct peripheral vasodilator action of losartan in patients with heart failure suggests that the vasodilatation induced by ACE inhibition is also probably caused, at least in part, through a reduction in the generation of angiotensin II. Recently, the ELITE study ${ }^{31}$ has shown that $\mathrm{AT}_{1}$ antagonism is associated with a lower mortality than ACE inhibition in elderly patients with heart failure. The mechanism of this benefit has not been fully elucidated but may be related to its more complete inhibition of angiotensin II action, and peripheral and systemic vasodilator actions may contribute.

In agreement with previous studies, ${ }^{32-34}$ we have additionally shown an attenuation of forearm vasoconstriction to lower body negative pressure in patients with heart failure. The mechanism of this impaired response is not a result of a reduction in peripheral sensitivity to noradrenaline, given the normal responsiveness to noradrenaline infusion in these patients. Heart failure is associated with increased sympathetic nerve outflow ${ }^{35}$ and suggests that the impaired response to lower body negative pressure may reflect increased basal activity attenuating the effect of further stimulation of the reflex. Alternatively, $15 \mathrm{~mm} \mathrm{Hg}$ of lower body negative pressure in patients with high cardiac filling pressures may not be sufficient to reduce the pressure in the atria or pulmonary arteries to enable unloading of the cardiopulmonary baroreceptors and stimulation of the reflex. Finally, these observations are also in keeping with the beneficial haemodynamic effects of peripheral venous pooling, which reduces cardiac preload, thereby improving the tension-pressure relation of the failing heart, perhaps even leading to peripheral vasodilatation. $^{34}$

A reduced cardiac output leads to increases in central sympathetic nerve outflow, ${ }^{35}$ circulating noradrenaline concentrations, ${ }^{36}$ and peripheral vascular resistance. ${ }^{37}$ It is well established that angiotensin II facilitates release of noradrenaline from nerve terminals in vitro. ${ }^{4}$ Even at doses insufficient to cause vasoconstriction directly, angiotensin II augments sympathetically mediated vasoconstriction in vivo ${ }^{3}$ through prejunctional release of noradrenaline. ${ }^{5}$ Thus there is an important potential for the renin-angiotensin and sympathetic nervous systems to act synergistically in the pathophysiology of heart failure. If basal concentrations of tissue or plasma angiotensin II augment normal sympathetically mediated vasoconstriction, then losartan would be expected to reduce the response to lower body negative pressure. Although this has been described in sodium deplete hypertensive patients, using the mixed antagonist and partial agonist saralasin, ${ }^{20}$ we have not detected an effect of losartan on vasoconstriction induced by lower body negative pressure, either in patients with heart failure or in healthy control subjects. However, there are some inconsistencies in the responses to angiotensin II 
infusion during lower body negative pressure $^{338} 39$ with some workers finding facilitation of prejunctional noradrenaline release only at high plasma angiotensin II concentrations of 25-97 fmol $/ \mathrm{ml} .^{38}$ Therefore, while the lack of an effect of losartan on the lower body negative pressure response may not have been unexpected in healthy controls with low plasma angiotensin II concentrations, it is perhaps surprising in patients with heart failure. Nevertheless, in the present study we were only able to show a trend for a reduction in blood flow with lower body negative pressure in patients with heart failure, so a small effect of losartan could have been missed. It also remains a possibility, though unlikely, that the induction of prejunctional noradrenaline release by angiotensin II is medi-

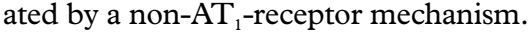

We have studied patients with moderate chronic heart failure receiving maintenance diuretic and ACE inhibitor treatment. Given that diuretic treatment can stimulate the reninangiotensin system, the acute withdrawal of ACE inhibition may cause a rebound increase in plasma angiotensin II. In this situation, the response to $\mathrm{AT}_{1}$ antagonism might be expected to be greater. However, our patient population had only a moderate rise in plasma angiotensin II concentrations and a normal responsiveness to exogenous angiotensin II infusion.

We have also shown, in agreement with previous work, ${ }^{212}$ that intra-arterial losartan has no effect on basal forearm blood flow or vascular resistance in healthy control subjects. The $95 \%$ confidence intervals indicate that if angiotensin II provides any contribution to basal tone in peripheral blood vessels of healthy people then it is rather small. It would appear, therefore, at least in Western societies maintained on a relatively high sodium diet, ${ }^{40}$ that angiotensin II is implicated in tonic adaptive responses rather than in the basal maintenance of peripheral resistance vessel tone in healthy man.

In summary, using intra-arterial losartan infusions, we have directly shown that angiotensin II makes an important contribution to the local maintenance of basal peripheral vascular tone in patients with heart failure but not in healthy controls. This would suggest that $\mathrm{ACE}$ inhibitors and angiotensin $\mathrm{AT}_{1}$ receptor antagonists cause vasodilatation at least in part through a direct action. In addition, we have shown hyporesponsiveness to sympathetic nervous system activation through baroreceptor unloading, which does not appear to be augmented by angiotensin II.

DEN is the recipient of a British Heart Foundation Junior Research Fellowship (FS/95009). We would like to acknowledge the assistance of Laura Flint, Neil Johnston, and Rhona Stephen.

1 Johnston CI. Angiotensin receptor antagonists: focus on losartan. Lancet 1995;346:1403-7.

2 Brough RB, Cowley AW, Guyton AC. Quantitative analysis of the acute response to hemorrhage of the reninangiotensin-vasoconstrictor feedback loop in areflexic dogs. Cardiovasc Res 1975;9:722-33.

3 Seidelin PH, Collier JG, Struthers AD, et al. Angiotensin II augments sympathetically mediated arteriolar constriction in man. Clin Sci 1991;81:261-6.

4 Cockcroft JR, O'Kane KPJ, Webb DJ. Tissue angiotensin generation and regulation of vascular tone. Pharmacol Ther 1995;65:193-213.

5 Hjemdahl P, Friberg P. Biochemical assessment of sympathetic activity and prejunctional modulation of noradrenaline release in humans. F Hypertens 1996;14:147-50.
6 Levine TB, Olivari MT, Garberg V, et al. Hemodynamic and clinical response to enalapril, a long-acting convertingenzyme inhibitor, in patients with congestive heart failure. Circulation 1984;69:548-53.

7 Creager MA, Massie BM, Faxon DP, et al. Acute and longterm effects of enalapril on the cardiovascular response to exercise and exercise tolerance in patients with congestive heart failure. 7 Am Coll Cardiol 1985;6:163-73.

8 The CONSENSUS trial study group. Effects of enalapril on mortality in severe congestive heart failure: results of the cooperative north Scandinavian enalapril survival study (CONSENSUS). N Engl f Med 1987;316:1429-32.

9 Cohn JN, Johnson G, Zeische S, et al. A comparison of enalapril with hydralazine-isosorbide dinitrate in the treatment of chronic congestive heart failure. $N \mathrm{Engl} 7 \mathrm{Med}$ 1991;325:303-10.

10 The SOLVD investigators. Effect of enalapril on survival in patients with reduced left ventricular ejection fractions and congestive heart failure. N Engl f Med 1991;325:293-302.

11 The SOLVD investigators. Effect of enalapril on mortality and the development of heart failure in asymptomatic patients with reduced left ventricular ejection fractions. $N$ Engl F Med 1992;327:685-91.

12 Drexler H, Kurz S, Jeserich $M$, et al. Effect of chronic angiotensin-converting enzyme inhibition on endothelial function in patients with chronic heart failure. Am f Cardiol 1995;76:13-18E.

13 Crozier I, Ikram H, Awan N, et al. Losartan in heart failure: hemodynamic effects and tolerability. Circulation 1995;91: 691-7.

14 Gottlieb SS, Dickstein K, Fleck E, et al. Hemodynamic and neurohumoral effects of the angiotensin II antagonist losartan in patients with congestive heart failure. Circulation 1993;88:1602-9.

15 Webb DJ. The pharmacology of human blood vessels in vivo. $\mathcal{I}$ Vasc Res 1995;32:2-15.

16 Benjamin N, Calver A, Collier J, et al. Measuring forearm blood flow and interpreting the responses to drugs and mediators. Hypertension 1995;25:918-23.

17 Haynes WG, Webb DJ. Contribution of endogenous generation of endothelin-1 to basal vascular tone in man. generation of endothelin-1
Lancet 1994;344:852-4.

18 Vallance P, Collier J, Moncada S. Effects of endotheliumderived nitric oxide on peripheral arteriolar tone in man. Lancet 1989;ii:997-1000.

19 Webb DJ. Sympathetic vasoconstriction and local converting enzyme activity within the upper limb circulation in man: studies with particular relevance to the action of angiotensin. London: University of London, 1990. (MD thesis.)

20 Taddei S, Virdis A, Mattei P, et al. Angiotensin II and sympathetic activity in sodium-restricted essential hypertension. Hypertension 1995;25:595-601.

21 Baan J, Chang PC, Vermeij P, et al. Effects of losartan on vasoconstrictor responses to angiotensin II in the forearm vascular bed. Cardiovasc Res 1996;32:973-9.

22 Newby DE, Masumori S, Johnston NR, et al. Endogenous angiotensin II contributes to basal peripheral vascular tone in sodium deplete but not sodium replete man. Cardiovasc Res 1997;36:268-75.

23 Wiinberg N, Walter-Larson S, Eriksen C, et al. An evaluation of semi-automatic blood pressure manometers against intra-arterial blood pressure. Fournal of Ambulatory Monitoring 1988;1:303-9.

24 Rolinski B, Bogner SJ, Goebel FD. Determination of endothelin-1 immunoreactivity in plasma, cerebrospinal fluid and urine. Res Exp Med 1994;194:9-24.

25 Morton JJ, Webb DJ. Measurement of plasma angiotensin II. Clin Sci 1985;68:483-4.

26 Cody RJ, Haas GJ, Binkley PF, et al. Plasma endothelin correlates with the extent of pulmonary hypertension in patients with chronic congestive heart failure. Circulation 992;85:504-9.

27 Goldstein DS, Feuerstein G, Izzo JL, et al. Validity and reliability of liquid chromatography with electrochemical detection for measuring plasma levels of norepinephrine and epinephrine in man. Life Sci 1981;28:467-75.

28 Dickstein K, Chang P, Willenheimer R, et al. Comparison of the effects of losartan on clinical status and exercise performance in patients with moderate or severe chronic heart failure. 7 Am Coll Cardiol 1995;26:438-45.

29 Cohn JC, Archibald DG, Ziesche S, et al. Effect of vasodilator therapy on mortality in chronic congestive heart failure. N Engl F Med 1986;314:1547-52.

30 Groves P, Kurz S, Just H, et al. Role of endogenous bradykinin in human coronary vasomotor control. Circulation 1995;92:3424-30.

31 Pitt B, Segal R, Martinez FA, et al. Randomised trial of losartan versus captopril in patients over 65 with heart failure (evaluation of losartan in the elderly study, ELITE). Lancet 1997;349:747-52

32 Levine TB, Francis GS, Goldsmith SR, et al. The neurohumoral and hemodynamic response to orthostatic tilt in patients with congestive heart failure. Circulation 1983;67: 1070-5

33 Ferguson DW, Abboud FM, Mark AL. Selective impairment of baroreflex-mediated vasoconstrictor responses in patients with ventricular dysfunction. Circulation 1984;69:451-60.

34 Nishian K, Kawashima S, Iwasaki T. Paradoxical forearm vasodilatation and haemodynamic improvement during vasodilatation and haemodynamic improvement during cardiopulmonary baroreceptor unloading in patient

35 Leimbach WN, Wallin BG, Victor RG, et al. Direct evidence from intraneural recordings for increased central sympa- 
thetic outflow in patients with heart failure. Circulation 1986;73:913-19.

36 Levine TB, Francis GS, Goldsmith SR, et al. Activity of the sympathetic nervous system and renin-angiotensin system assessed by plasma hormone levels and their relationship to hemodynamic abnormalities in congestive heart failure. Am f Cardiol 1982;49:1659-66.

37 Kluger J, Cody R, Laragh J. The contribution of sympathetic tone and the renin-angiotensin system to severe congestive heart failure: response to specific inhibitors (prazosin and captopril). Am f Cardiol 1982;49:1667-72.

38 Clemson B, Gaul L Gubin SS, et al. Prejunctional angiotensin II receptors. F Clin Invest 1994;93:684-91.

39 Goldsmith SR, Rector TS, Bank AJ, et al. Effect of angiotensin II on noradrenaline release in the human forearm. Cardiovasc Res 1994;26:663-6.

40 MacGregor GA. Dietary sodium and blood pressure [letter]. Lancet 1994;343:545-6.

\section{IMAGES IN CARDIOLOGY}

\section{Unruptured right sinus of Valsalva aneurysm}

The diagnosis of sinus of Valsalva aneurysm is usually made when acute congestive heart failure occurs following a rupture of the aneurysm into the right ventricle or the right atrium. We report a rare case of unruptured right sinus of Valsalva aneurysm.

A 73 year old man was admitted to our hospital because of progressive dyspnoea on exertion. On examination his pulse was regular at 84 beats/min and blood pressure 150/ $46 \mathrm{~mm} \mathrm{Hg}$. To and fro murmur of Levine $2 / 6$ grade was heard at the second right sternal border. ECG showed left ventricular hypertrophy with ST-T changes, and chest radiography showed moderate cardiomegaly (cardiothoracic ratio 0.74 ) and bilateral pleural effusion.
Aortic regurgitation was thought to be the cause of his congestive heart failure. However, transoesophageal echocardiography (left) revealed a large aneurysmal change of the right sinus of Valsalva as well as severe aortic regurgitation. A protrusion of the aneurysm into the right ventricle appeared to obstruct blood flow to the outflow tract. A shunt flow was not detected. Intravenous digital subtraction angiography confirmed the diagnosis of unruptured right sinus of Valsalva aneurysm, demonstrating an impressive large filling defect within the right ventricle (right). (LA, left atrium; LV, left ventricle; SVA, sinus of Valsalva aneurysm; PA, pulmonary artery.)
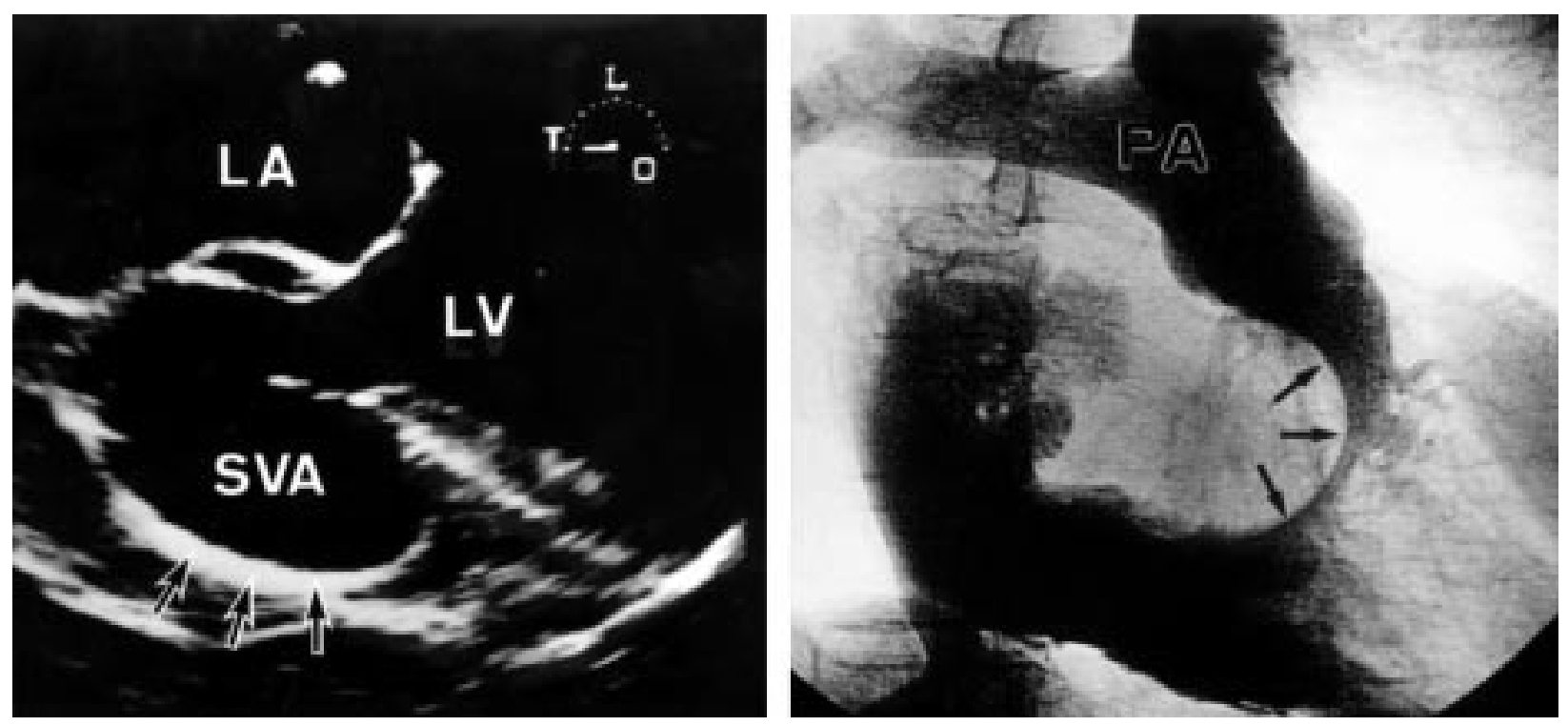

H KITAOKA N HITOMI Y L DOI 